\title{
Una reina de novela: Isabel de Inglaterra y la ejemplaridad en Cervantes, Ribadeneyra y Yepes ${ }^{\top}$ A Novel Queen: Elizabeth Tudor and Exemplarity in Cervantes, Ribadeneyra, and Yepes
}

\section{Deborah Forteza}

Grove City College

ESTADOS UNIDOS

fortezadr@gcc.edu

[Hipogrifo, (issn: 2328-1308), 6.2, 2018, pp. 75-86]

Recibido: 24-02-2017 / Aceptado: 29-03-2017

DOI: http://dx.doi.org/10.13035/H.2018.06.02.08

Resumen. Este ensayo analiza la ejemplaridad cervantina desde La española inglesa en relación a la Historia eclesiástica del cisma de Inglaterra del jesuita Pedro de Ribadeneyra y a la Historia particular de la persecución de Inglaterra, por fray Diego de Yepes. El ensayo propone que La española inglesa sugiere una alternativa a la ejemplaridad medieval de la hagiografía empleada en estas historias y a cambio propone ejemplos novelísticos complejos. Esta estrategia cervantina se ve en la transformación del personaje de Isabel de Inglaterra desde una figura monstruosa y estática a un personaje novelesco.

Palabras clave. Novelas ejemplares; Isabel de Inglaterra; Siglo de Oro; ejemplaridad, historias eclesiásticas; Cervantes.

Abstract. This essay analyzes Cervantes' idea of exemplarity through La española inglesa in relation to Historia eclesiástica del cisma de Inglaterra by the jesuit Pedro de Ribadeneyra and Historia particular de la persecución de Inglaterra by fray Diego de Yepes. The essay argues that La española inglesa suggests an alternative to the medieval exemplarity of hagiography employed in these histories, and proposes instead complex, novelistic examples. This Cervantine strategy is illus-

1. Este artículo es el resultado de una comunicación presentada en el Congreso Internacional «Cervantes, su obra y su tiempo. Cuarto centenario (1616-2016)», organizado por el Grupo de Investigación Siglo de Oro (GRISO), Pamplona, Universidad de Navarra, diciembre de 2016. 
trated in the transformation of the character of Elizabeth Tudor from a monstrous, static figure to a novelized character.

Keywords. Exemplary novels; Elizabeth Tudor; Spanish Golden Age; Exemplarity; Ecclesiastical histories; Cervantes.

Uno de los temas más debatidos en los estudios cervantinos es qué quiso proponer Cervantes en cuanto a la ejemplaridad con su colección tan diversa de «novelas ejemplares». En este ensayo propongo estudiar la ejemplaridad cervantina desde La española inglesa en relación a textos contemporáneos importantes que hoy no se suelen estudiar juntos. Me refiero a la Historia eclesiástica del cisma de Inglaterra $(1588,1593)$ del jesuita Pedro de Ribadeneyra y a la Historia particular de la persecución de Inglaterra (1599), por fray Diego de Yepes, confesor de Felipe II y Teresa de Ávila². Si bien entre las historias y la novela hay ciertas diferencias genéricas y de objetivos, mi punto de comparación se centra en la forma en que los tres textos adaptan la historia de un personaje para extraer una enseñanza. Mi tesis es que La española inglesa sugiere una alternativa a la ejemplaridad medieval de la hagiografía empleada en estas historias y a cambio expone ejemplos novelísticos complejos. Para ilustrar esta estrategia cervantina, y solo como introducción al tema, voy a enfocarme en algunos aspectos de la transformación del personaje de Isabel de Inglaterra desde una figura monstruosa y estática a un personaje novelesco.

\section{RIBADENEYRA, YEPES Y CERVANTES}

Aunque no hay evidencia de que Cervantes leyó las historias de Ribadeneyra y Yepes, las obras fueron tan ampliamente difundidas en España que debió de conocerlas. Solo seis años después de la primera publicación del texto de Ribadeneyra, había al menos dieciséis ediciones registradas en la Península Ibérica, sin incluir las muchas traducciones del texto base latino Schismatis Anglicani ${ }^{3}$ de Nicholas Sander que circularon en Europa ${ }^{4}$. Además, tanto Lope de Vega como Calderón de

\footnotetext{
2. Para una introducción a la comparación entre Ribadeneyra y Cervantes, ver mi artículo, «Representaciones del cisma de Inglaterra en el Siglo de Oro: Ribadeneira y Cervantes».

3. Cito en este ensayo la traducción al inglés de David Lewis, Rise and Growth of the Anglican Schism (1877)

4. Allison and Rogers, 1989, pp. 138-139. Entre 1588 y 1594 se publicaron once ediciones de la primera parte, mientras que cinco eran ediciones de la segunda parte. Estas obras aparecen en las bibliotecas de Francisco Hurtado de Mendoza-el Marqués de Almazán y Virrey de Navarra-y Diego Sarmiento de Acuña, el primer Conde de Gondomar. El catálogo de la biblioteca del Marqués de Almazán incluye una copia de la Historia de Ribadeneyra, pero no lista la Historia particular de la persecución de Yepes ya que ésta última no sería publicada hasta 1599, algunos años después de la muerte del Marqués en 1591 (Bouza, 1999, pp. 272, 281, 298). El inventario de 1623 de la biblioteca de Diego Sarmiento de Acuña (hoy guardado en la Biblioteca Real de Palacio en Madrid) lista copias de las historias eclesiásticas inglesas de Pedro de Ribadeneyra y Diego de Yepes.
} 
la Barca escribieron sobre Inglaterra basados en estas historias ${ }^{5}$, así que lo extraño sería que Cervantes no las conociera. Pero aún más importante es el hecho de que La española inglesa sugiere varias conexiones con estas historias eclesiásticas españolas que sus lectores originales hubieran reconocido.

La protagonista, Isabela, a quien luego llaman, «la española inglesa», es una niña española llevada cautiva a Inglaterra durante el saqueo de Cádiz por el capitán inglés Clotaldo, quien, junto a su esposa Catalina, adopta a la niña como hija. Por Providencia, Clotaldo y su noble familia son «católicos secretos», y la española puede preservar su fe y su lengua natal además de aprender a hablar inglés «como si hubiera nacido en Londres» ${ }^{6}$. Por miedo a ser descubiertos como católicos, los ingleses esconden a la niña de la reina, pero cuando Isabela crece y se enamora de Ricaredo, el hijo de Clotaldo y Catalina, la joven es llevada al palacio para obtener la bendición de Isabel Tudor para casarse. La hermosura y discreción de la española fascinan a la reina, quien la retiene en su corte hasta que Ricaredo pruebe en alta mar que es digno de ella consiguiendo tesoros para la reina. La pareja luego supera una serie de obstáculos para al fin conseguir su unión, y la moraleja de la historia es que la virtud y la hermosura pueden enamorar hasta los enemigos y que Dios puede cambiar desgracias en beneficios. Los temas más importantes de la narrativa son el de la providencia, perseverancia y paciencia en la adversidad - temas también esenciales en la segunda parte de la Historia de Ribadeneyra y en el volumen de Yepes.

Además de que comparten la descripción de la Inglaterra isabelina, tanto las historias de Ribadeneyra y Yepes como La española inglesa se centran en el exemplum. Según Maravall, la mayor parte de la literatura didáctica medieval eran colecciones de exempla, y en los siglos dieciséis y diecisiete estas colecciones fueron continuamente reeditadas en toda Europa, mostrando así la centralidad del exemplum en la literatura de este tiempo ${ }^{7}$. Los retóricos que influyeron en España, como Erasmo, Juan Luis Vives y Saavedra Fajardo, alegaron que el exemplum era superior al precepto para mover a las audiencias por sus narrativas vívidas, especialmente cuando estas eran históricas y más cercanas a la audiencia ${ }^{8}$. Maravall presenta al trabajo de Ribadeneyra como un «caso clarísimo» de argumentación por exempla, donde las historias concretas tienen la fuerza de la prueba empírica para apoyar la doctrina propuesta ${ }^{9}$, por ende, la historia de Ribadeneyra se podría considerar un modelo popular del uso del exemplum. No obstante, aunque el enfoque de Cervantes en el exemplum por sí solo no conecta su texto con el de Ribadeneyra, el hecho

\footnotetext{
5. Tanto La cisma de Ingalaterra (1626) de Calderón como la comedia de Lope El amor desatinado (1597) claramente emplean la historia de Ribadeneyra como fuente primaria. Aunque la conexión de Lope no es tan directa en sus obras La Dragontea (1598) y La corona trágica (1627), estas obras también muestran vínculos textuales y temáticos con las historias eclesiásticas. Ver mi artículo, «Beasts, Harpies, \& Medeas: Tudor Representations in Lope \& Calderón».

6. Cervantes, Novelas ejemplares, p. 244.

7. Maravall, 1983, pp. 205-206.

8. Ver Pineda, 2005, pp. 33-37; Maravall, 1983, pp. 208, 215.

9. Maravall, 1983, pp. 206, 210
} 
de que La española inglesa destaca ejemplos de católicos de la Inglaterra isabelina parece mostrar un vínculo entre estas obras.

De hecho, Ribadeneyra y Yepes justamente modificaron el texto latino del católico inglés Sander para que tuviera un riguroso énfasis en el exemplum, es decir, una lección moral derivada de personas y acontecimientos. En la dedicatoria al Príncipe, en el prólogo al lector, y a lo largo de su trabajo, Ribadeneyra insiste en la función de los ejemplos que incluye como modelos: «para tener delante, para huir de los malos e imitar y seguir los buenos» ${ }^{10}$. Yepes también concluye diciendo que su propósito al escribir es «mostraros con ejemplo de esta persecución, cuán temidos han de ser los juicios de Dios, y cuán reverenciados los secretos de su providencia, y su amada eterna bondad» ${ }^{11}$.

Del mismo modo, La española inglesa se centra en el exemplum, especialmente aplicado a los lectores católicos y a la persecución inglesa. El censor que aprobó la colección de Novelas ejemplares donde se publicó la novela escribió que, además de entretener, las historias «enseñan con sus ejemplos a huir vicios y seguir virtudes» ${ }^{12}$. Este es el sentido del exemplum medieval también empleado en las historias eclesiásticas, aunque el uso cervantino varía esta estrategia literaria, haciendo el exemplum más complejo y ambiguo, probablemente en respuesta a una insatisfacción barroca con los ejemplos ${ }^{13}$. Cervantes ya había problematizado la ejemplaridad en el Quijote ${ }^{14}$ y también en las novelas ejemplares, ya que algunas historias no tienen una lección explícita y otras plantean problemas morales en lugar de resolverlos ${ }^{15}$. Por lo tanto, La española inglesa parece estar respondiendo al exemplum moral como es usado por Ribadeneyra y Yepes con una medida de ambigüedad que mantiene en juego la estética y el valor de entretenimiento novelístico. Esto parece claro en la conclusión, donde el narrador resume la lección de la historia:

Esta novela nos podría enseñar cuánto puede la virtud y cuánto la hermosura, pues son bastante juntas y cada una de por sí a enamorar aun hasta los mismos enemigos, y de cómo sabe el cielo sacar de las mayores adversidades nuestras, nuestros mayores provechos ${ }^{16}$.

Este pasaje se refiere explícitamente a la capacidad de enseñar de la historia, y, sin embargo, el uso del verbo condicional podría parece quitar el énfasis a la di-

\footnotetext{
10. Ribadeneyra, Historias de la contrarreforma, p. 1195.

11. Yepes, Historia particular de la persecucion de Inglaterra, p. 893

12. Cervantes, Novelas ejemplares, p. 45.

13. Maravall arguye que los autores barrocos reapropiaron el exemplum medieval con «forzosas novedades» para restaurar el orden tradicional fracturado (1983, p. 210). Stierle compara el uso del exemplum en Montaigne, Bocaccio y Petrarca con el de Cervantes y sitúa a las Novelas ejemplares en un momento de «crisis de ejemplaridad».

14. Cruz, 2014, pp. 18-19; Forcione, 1989, p. 334

15. Para ejemplos específicos de preguntas planteadas dentro de diferentes novelas ejemplares, ver Boyd, 2005, pp. 29-40.

16. Cervantes, Novelas ejemplares, p. 283.
} 
mensión didáctica de la obra. El verbo condicional puede también significar que el lector podría aprender solamente si lee cuidadosamente, como el prólogo sugiere. Sin embargo, dado el interés de Cervantes por el entretenimiento y la estética en la literatura, así como su ambigüedad con el exemplum, parece admisible sugerir que la novela aquí cuestiona el énfasis didáctico de la literatura. En otras palabras, la novela podría enseñar algo útil para el lector, pero esta lección no parece esencial. Si Cervantes hubiera querido resaltar el exemplum, podría haber usado otras construcciones que serían más cercanas a las frases inequívocas que emplean Ribadeneyra y Yepes, como «esta novela nos muestra» O «vese en esta novela». El efecto de la ambigüedad de la terminología de Cervantes parece, por un lado, satisfacer a aquellos que creen que las novelas deben tener una lección moral para ser valiosas, pero por el otro, socavar sutilmente esa posición. El hecho de que La española inglesa tenga una lección explícita -a diferencia de la mayoría de las Novelas ejemplares - indica que Cervantes está interesado en la ejemplaridad moral y quizás esté respondiendo a los exempla de Ribadeneyra. Además, es posible que haya una conexión textual entre estas obras, ya que la conclusión de la novela y de la Historia son extrañamente semejantes. La segunda parte de la Historia de Ribadeneyra concluye: «En lo cual todo se ve la inefable misericordia e inmensa bondad del Señor, que de los mayores males del mundo saca mayores bienes» ${ }^{17}$.

\section{LA TRANSFORMACIÓN DE ISABEL}

Otro indicio de que Cervantes podría estar respondiendo a los exempla de las historias se encuentra en los personajes ejemplares, como por ejemplo el de Isabel. Como es bien sabido, la reina de Inglaterra era odiada en España, especialmente después de la derrota de la Armada Invencible. Casi toda la literatura publicada durante la vida de Cervantes la presenta como a una tirana y aun como un monstruo. Por ejemplo, en La Dragontea Lope de Vega la llama «la cruel Medea» y en Rimas humanas, «Jezabel»y «arpía» ${ }^{18}$. Esta representación monstruosa de la reina parece derivada, o al menos popularizada principalmente por la Historia de Ribadeneyra publicada en dos partes en 1588 y 1593. En ella se dice de Isabel: «Vemos a una mujer, hija y nieta de Enrique VIII, e hija y hermana de Ana Bolena...como un abominable monstruo e ídolo, asentada en el templo de Dios, tomando el oficio y nombre de gobernadora y cabeza de la Iglesia» ${ }^{19}$.

Ribadeneyra explica en su prefacio «al cristiano y piadoso lector» que, como jesuita, su deber es defender al catolicismo romano y oponerse a los herejes, refiriéndose a Enrique VIII, Ana Bolena y a su hija Isabel, de quien también dice:

Siguiendo las pisadas de tales padres e hinchando la medida de ellos, con extraordinaria crueldad y tiranía persigue nuestra santa fe católica, apostólica y Ro-

17. Ribadeneyra, Historias de la contrarreforma, p. 1325.

18. Lope, La Dragontea, pp. 158, 162; Rimas humanas, p. 523. Ver Olid Guerrero, 2013, pp. 50-52.

19. Ribadeneyra, Historias de la contrarreforma, p. 1196. 
mana, y hace carnicería de los que la profesan y enseñan, atormentándolos, descoyuntándolos y despedazándolos con atrocísimos linajes de penas y muertes ${ }^{20}$.

Esta breve descripción de la condición de los católicos en Inglaterra en ese período encapsula toda la violencia, injusticia y prejuicio que Ribadeneyra le atribuye a la reina y que se explica en detalle en el resto de su volumen. Isabel no solo «sigue las pisadas de sus padres» pero también hincha la medida de ellos ${ }^{21}$ de modo que los cargos contra sus padres le son imputados a ella y son aún mayores que los de aquéllos: su ambición, lujuria e hipocresía, su rechazo del Papa y de la verdadera Iglesia, su robo de los templos, y su tiranía cruel y persecución de católicos. Ribadeneyra especifica las acciones de Isabel contra los católicos con verbos y adjetivos perturbadores como extraordinaria crueldad, hacer carnicería, atormentar, descoyuntar, despedazar y atrocísimos, no dando lugar a que la reina muestre moderación o misericordia hacia los católicos.

La Historia particular de Yepes, por su parte, se publica un poco después que la Historia de Ribadeneyra, pero mantiene la misma perspectiva en cuanto a la reina inglesa. Yepes toma en cuenta las desventajas que Isabel ha tenido (en su nacimiento, su sexo y sus consejeros) que la llevaron a su estado actual, pero aún así la pone en una posición irredimible:

Resolviose de dejar a Dios por el mundo, y el Reino eterno, y de su bienaventuranza, por otro miserable y temporal; y así se entregó sin freno a los deleites y regalos, y el gobierno a los hombres desalmados, que su desventura y los pecados de sus padres le habían dado por consejeros ${ }^{22}$.

Para Yepes, Isabel le ha dado la espalda a Dios, se ha entregado completamente a la lujuria, y ha entregado su reino a hombres despiadados. Ya que Isabel no va a dejar su reino temporal ni negar sus pasiones, debe oponerse al Papa y a los que le obedecen y no puede tolerarlos ni mostrar afecto por ellos. Es más, que Isabel, siendo reina, no tenga control sobre sus pasiones es precisamente lo que la convierte en una tirana según los tratados de príncipes cristianos de la época23. Por ende, la Isabel de Ribadeneyra y Yepes es estática, monstruosa, cruel y tirana y advierte a los cristianos lectores del peligro de darle la espalda a Dios y a su Iglesia: o sea, es un exemplum medieval de conducta a evitar, tanto para un monarca como para un súbdito cristiano.

20. Ribadeneyra, Historias de la contrarreforma, p. 900.

21. La expresión hinchando la medida de los pecados de un ancestro evoca la acusación de Jesús hacia los escribas y fariseos en Mateo, 23, vv. 29-32 por haber matado a los profetas: «Ay de vosotros Escribas y Fariseos, hipócritas: porque edificáis los sepulcros de los profetas, y adornáis los monumentos de los justos. Y decís, Si fuéramos en los días de nuestros padres, no hubiéramos sido sus compañeros en la sangre de los profetas. Así que testimonio dais a vosotros mismos, que sois hijos de aquellos que mataron a los profetas. Vosotros también henchid la medida de vuestros padres» (Biblia del Oso, 1569). 22. Yepes, Historia particular de la persecución de Inglaterra, p. 12.

23. Arellano, 2006, pp. 161-162; Quintero, 2008, p. 83. 
Sin embargo, la Isabel de La española inglesa es considerablemente más compleja. Canavaggio ha dicho que Cervantes «nos da del mundo musulmán una representación infinitamente más matizada que la deformación caricaturesca...[de] los escritos polémicos de sus contemporáneos» ${ }^{24}$, lo cual también parece aplicarse a su representación de los ingleses y de su reina y al mismo tiempo complica la ejemplaridad medieval. La novela de Cervantes alude a la persecución de los católicos ingleses en la consternación de Clotaldo y su familia en no ser descubiertos, pero el texto no es claro sobre qué sucede con los infractores-si hay penas monetarias o encarcelamiento o muerte, aunque el inglés sugiere que podrían ser ejecutados:

Clotaldo buscaba modos que pudiesen dar ánimo a su mucho temor, y no los hallaba sino en la mucha confianza que en Dios tenía y en la prudencia de Isabela, a quien encomendó mucho que por todas las vías que pudiese excusase el condenarlos por católicos: que puesto que estaban prontos con el espíritu a recibir martirio, todavía la carne enferma rehusaba su amarga carrera ${ }^{25}$.

Clotaldo parafrasea las palabras de Jesús en Mateo, 26, $41^{26}$ para justificar su flaqueza ante las consecuencias de exponer su fe y para explicar por qué él y su familia son católicos secretos.

Estas referencias directas e indirectas al temor que los católicos experimentaron bajo Isabel se corroboran en los relatos de las historias eclesiásticas españolas. El volumen de Ribadeneyra incluye una carta del jesuita Edmund Campion de 1580 que enumera las razones por las que los católicos estaban ansiosos: «Estando escribiendo ésta, se embravece la persecución cruelísima; la casa está triste, porque no se habla sino de la muerte o de las prisiones, o del perdimiento de los bienes y de la huida de los de ella; y con todo esto van adelante animosamente» ${ }^{27}$. Campion observa que, aunque los católicos perseveran, a medida que la persecución aumenta, los temas de conversación se reducen a la muerte, el encarcelamiento, el exilio y la pérdida de las posesiones, lo que causa congoja. Del mismo modo, la familia de Clotaldo se angustia (amarga carrera), y su conversación se enfoca en evitar la exposición de su religión. No obstante, la ambigüedad del castigo de los católicos en la novela menoscaba los sufrimientos descritos por Ribadeneyra y Yepes que son fundamentales para afirmar que Isabel es una tirana cruel. En la Historia, después de presentar la ejecución de María Estuarda como la prueba definitiva de la crueldad de Isabel, Ribadeneyra afirma:

Como la herejía es un monstruo infernal, todos los frutos que nacen de ella son monstruosos e infernales. Y si para conocer esta verdad no bastaban los innumerables ejemplos que antes teníamos de crueldad, violencia y tiranía que han usado 
los herejes en nuestros tiempos, éste solo basta por todos, y bastará en todos los siglos venideros ${ }^{28}$.

Ribadeneyra aquí, casi al final de la primera parte de su libro, señala que, aunque la ejecución de María es un ejemplo extremo de impiedad, cada acto brutal contra los católicos constituye una prueba de la crueldad de Isabel y, por lo tanto, vale la pena documentar cada detalle para que todos lo sepan. En contraste, el terror de Clotaldo en la novela, en última instancia, parece superfluo porque ningún católico es descubierto o castigado y la reina actúa favorablemente hacia los españoles.

Una explicación posible para la falta de detalle en La española inglesa es que Cervantes no sabía mucho acerca de la situación de los católicos en Inglaterra, pero la información que habría reunido durante su estancia en Valladolid alrededor de 1604 y de las historias eclesiásticas hace que esa afirmación sea poco probable 29 . Otra razón más contundente podría ser que esos detalles simplemente no eran relevantes para la historia que Cervantes pretendía contar. Sin embargo, cuando se consideran estas omisiones junto a las muchas asociaciones positivas hechas para Isabel, la novela parece atenuar deliberadamente la crueldad de Isabel Tudor tan viva en las historias de Ribadeneyra y Yepes ${ }^{30}$.

De hecho, la Isabel de Cervantes tiene varios rasgos positivos. Es justa y le concede a Ricaredo una oportunidad razonable para demostrar su valor y ganar a Isabela. También guarda su palabra: le da a Ricaredo lo que le prometió porque según la novela es «imposible.... [para la reina] romper su palabra» ${ }^{31}$. Isabel tampoco pervierte la justicia, incluso en contra de sus intereses. Cuando su camarera le dice que envenenó a la española porque «en matar a Isabela hacía sacrificio al cielo, quitando de la tierra a una católica», la reina la castiga «como su delito merece», en vez de excusarla ${ }^{32}$. Olid Guerrero dice que esta acción de castigar un súbdito inglés por una española, desde un punto de vista maquiavélico, es potencialmente un «error político» y muestra que la reina guarda su palabra a toda costa y tiene un balance ideal entre una reina maquiavélica y una cristiana ${ }^{33}$. Si es así, Cervantes podría sugerir que Isabel es el exemplum del monarca cristiano en un giro irónico al enfoque de Ribadeneyra y Yepes en los tratados de príncipes ${ }^{34}$.

28. Ribadeneyra, Historias de la contrarreforma, p. 1186; énfasis agregado.

29. Johnson documenta la estancia de Cervantes en Valladolid y su conocimiento de eventos ingleses, especialmente de la visita del Almirante Charles Howard y su séquito en 1605 (1998, pp. 390-396). En ese período Valladolid era el centro de residencia de la corte, de las negociaciones anglo-hispanas y del colegio inglés San Albano que preparaba exiliados ingleses a volver como misioneros católicos a Inglaterra, muchos de los cuales fueron mártires y sus muertes se registran en las historias de Ribadeneyra y Yepes.

30. Las razones políticas o ideológicas por las cuales Cervantes podría haber alterado la imagen negativa de Isabel son varias y exceden los propósitos de este artículo.

31. Cervantes, Novelas ejemplares, p. 265

32. Cervantes, Novelas ejemplares, pp. 269, 272.

33. Olid Guerrero, 2013, pp. 46-47.

34. El argumento de Domínguez que la historia eclesiástica de Ribadeneyra parece desviarse de la norma y proporciona «verdaderos ejemplos de proezas reales» en «una trifecta de reinas» de Catalina 
Pero lo más significativo es que, a diferencia de las representaciones en Ribadeneyra y Yepes, la reina de Cervantes reconoce la virtud y la belleza en sus enemigos y es capaz de respetar y aún amarles. Por esta cualidad, la reina puede admirar, en vez de resentir, la lealtad de Isabela a la religión de sus padres y despedir a los españoles «con mucho amor» ${ }^{35}$. De hecho, este es el aspecto más discordante entre Cervantes y los eclesiásticos Ribadeneyra y Yepes. Además, la moraleja de la novela que la belleza y la virtud pueden incluso enamorar a los enemigos alude a la posibilidad de amistad entre adversarios y es muy diferente a la de las historias eclesiásticas que suponen que los enemigos son completamente irredimibles y solo se puede aprender de su destrucción.

La configuración de Isabel se hace aún más compleja cuando Cervantes la convierte en el doble de Isabela. Al otorgarle a la reina cualidades positivas se elimina cierta distancia entre la española y la reina y se apoya la duplicación en el texto, ya que la Isabel de Ribadeneyra sería demasiado opuesta para servir de doble a la joven española ${ }^{36}$. Sin duda, la novela ostenta la obsesión barroca con los reflejos tan frecuente en las obras cervantinas: la española y la reina llevan el mismo nombre, ambas manifiestan virtudes cristianas, ambas son sabias y veraces, y las dos se admiran mutuamente a pesar de ser enemigas. En algunos aspectos, son opuestas -española/inglesa, católica/protestante, reina/esclava- y estas oposiciones complican la correspondencia porque no está claro en qué punto el paralelismo evoca similitudes o diferencias o cuándo es simplemente irónico ${ }^{37}$.

Es más, los reflejos de Isabela e Isabel no son solo entre ellas: Isabela refleja a la Virgen y posiblemente a la amada reina católica, y por extensión, la Reina Isabel participaría en ese reflejo ${ }^{38}$. También, este juego de refracciones pareciera extenderse a ciertas alusiones a monarcas de otros géneros y textos, como el Faraón y el Salomón de la Biblia. La generosidad de la reina inglesa al dar la bienvenida a los padres de Isabela evoca la actitud del Faraón hacia la familia del patriarca José cuando llegan a Egipto. Cuando Ricaredo vuelve con regalos y alguien dice: «las [dádivas] que ha traído Ricaredo han ablandado el duro corazón de nuestra reina» ${ }^{39}$, la referencia a la dureza de corazón también sugiere el epitafio de Faraón, narrado en el libro del Éxodo y reiterado por San Pablo ${ }^{40}$. La grandeza de Isabel -que Ricaredo dice que los padres de Isabela vinieron a ver- y su sabiduría incluso podrían sugerir la grandeza de Salomón que la Reina de Sabá alabó41 .

de Aragón, María Tudor y María Estuarda (2015, pp. 10-11) haría que la inversión de Cervantes sea más irónica.

35. Cervantes, Novelas ejemplares, p. 270.

36. Para un análisis detallado sobre la duplicación en la historia ver Johnson, 1988, pp. 398-400; Collins, 1996, pp. 59-60; Isabel Torres, 2005.

37. Johnson considera estas correspondencias como «ecuaciones reversibles», 1988, pp. 398-399).

38. Isabel ya era conocida como «la Reina Virgen» y su comparación con la Virgen María se subraya en The Faerie Queene (1590) de Edmund Spenser.

39. Cervantes, Novelas ejemplares, p. 262.

40. Éxodo, 4, 21-22; 8, 19; 14, 4; Romanos, 11, 17-18.

41. 1 Reyes, 10, 1-13; 2 Crónicas, 9, 1-12; Mateo, 12, 42; Lucas, 11, 31. 
Aunque estas conexiones hoy parezcan tenues, eran copiosas en la literatura católica y especialmente en las historias eclesiásticas de Sander, Ribadeneyra y Yepes. Estas historias vinculan a Enrique VIII y a su hija Isabel justamente con estos monarcas bíblicos. Enrique es como el sabio y piadoso Salomón que cayó en idolatría por la seducción de mujeres, y especialmente por una: Ana Bolena ${ }^{42}$. La dureza de Enrique e Isabel contra los católicos y su persecución se asemeja a los intentos vanos del Faraón de destruir a los judíos ${ }^{43}$. Dadas estas asociaciones de Isabel y su padre, las conexiones entre La española inglesa y las historias eclesiásticas nuevamente parecen demasiado fuertes como para ser coincidencia y Cervantes parece jugar con las expectativas del lector creando asociaciones positivas entre la reina inglesa y estas figuras bíblicas.

En lugar de vincular a Isabel con el Faraón tirano de la historia de Moisés, como hacen Ribadeneyra y Sander, Cervantes la pone en el lugar del Faraón generoso anterior que promovió a José y salvó a los judíos de la extinción durante la gran sequía. Además, aunque la novela menciona el duro corazón de la reina conectándola a la tiranía del Faraón posterior, también se dice que su corazón se ha ablandado, lo cual ya contrasta con el rey bíblico, quien es conocido por nunca haberse doblegado. Aún si la comparación con Salomón en la novela es intencional, Isabel aparece no como el monarca que ha caído en idolatría por sus pecados, sino como el gran y sabio Salomón. Como es característico de Cervantes, estas alusiones están llenas de ironía y se oponen al retrato de la reina monstruosa y tirana en Ribadeneyra y al argumento de Yepes que Isabel se había rendido completamente a sus pasiones. En La española inglesa aún si la reina es un poco dura de corazón, está en control de sus pasiones, es generosa con Isabela, guarda su palabra, e imparte justicia sin prejuicios.

\section{CONCLUSIÓN}

Como sugiero en este artículo, tanto el tema de la Providencia y el sufrimiento de los católicos ingleses como el énfasis en el exemplum de las historias de Ribadeneyra y Yepes y La española inglesa provocarían conexiones espontáneas en los lectores originales. Por ello, al analizar la ejemplaridad en La española inglesa es posible conjeturar que Cervantes parece explorar cómo la historia, o una representación ficticia de ella, puede enseñar sin estar esclavizada a la caracterización estática de la hagiografía. Aún las asociaciones bíblicas pueden tornarse positivas o negativas, como lo demuestran los casos del Faraón y Salomón. Además, Cervantes muestra que los exempla como Isabel e Isabela pueden ser complejos y complementarios, en vez de antitéticos - que pueden reflejarse mutuamente en ciertos aspectos, mientras que se oponen en otros. Cervantes también pareciera sugerir que los reflejos pueden ser amplificados casi infinitamente, evocando figuras diversas en textos múltiples, y quizás esto insinúa que se puede encontrar

42. Highley, 2005, p. 162; Ribadeneyra, Historias de la contrarreforma, p. 975; Sander, Rise and Growth of the Anglican Schism, p. 118.

43. Ribadeneyra, Historias de la contrarreforma, pp. 994, 1201, 1306. 
personajes virtuosos en cualquier lugar y a ambos lados de fronteras religiosas y nacionales. Al final del día, La española inglesa parece unir el exemplum moral que la virtud será recompensada y que la hermosura y el amor superarán enemistades, y el exemplum estético que las buenas novelas pueden enseñar, pero que su belleza artística quizás es suficiente en sí misma.

\section{BIBLIOGRAFÍA}

Allison, Anthony F., y David M. Rogers, The Contemporary Printed Literature of the English Counter-Reformation between 1558 and 1640: An Annotated Catalogue, vol. 1, Aldershot, Scolar Press, 1989.

Arellano, Ignacio, «"Decid al rey cuánto yerra". Algunos modelos de mal rey en Calderón», en El teatro clásico español a través de sus monarcas, ed. Luciano García Lorenzo, Madrid, Fundamentos, 2006, pp. 149-180.

Bouza, Fernando, «Docto y devoto: La biblioteca del Marqués de Almazán y Conde de Monteagudo (Madrid, 1591)», Hispania-Austria II: die Epoche Philipps II (1556-1558), ed. Friedrich Edelmayer, Vienna/Munich, Verlag fur Geschichte und Politik/R. Oldenbourg Verlag: 1999, pp. 247-308.

Boyd, Stephen F., «Introduction», en A Companion to Cervantes' Novelas ejemplares, ed. Stephen F. Boyd, Woodbridge (Suffolk), Tamesis, 2005, pp. 1-46.

Canavaggio, Jean, Cervantes, trad. Mauro Armiño, Madrid, Espasa Calpe, 1987.

Cervantes Saavedra, Miguel de, Novelas ejemplares I, ed. Harry Sieber, Madrid, Cátedra, 1980.

Collins, Marsha S., «Transgression and Transfiguration in Cervantes's La española inglesa», Cervantes. Bulletin of the Cervantes Society of America, 16.1, 1996, pp. 54-73.

Cruz, Anne J., «Cervantes's Novelas ejemplares: Table of Trucos, Tricks of the Trade», Cervantes. Bulletin of the Cervantes Society of America, 34.1, 2014, pp. 15-39.

Domínguez, Freddy C., «History in Action: The Case of Pedro de Ribadaneyra's Historia ecclesiastica del scisma de Inglaterra», Bulletin of Spanish Studies, 93.1, 2015, pp. 1-26.

Forcione, Alban K., «Afterword: Exemplarity, Modernity, and the Discriminating Games of Reading», Cervantes's «Exemplary Novels» and the Adventure of Writing, ed. Michael Nerlich y Nicholas Spadaccini, Minneapolis (MN), Prisma Institute, 1989, pp. 331-351.

Forteza, Deborah, «Representaciones del cisma de Inglaterra en el Siglo de Oro: Ribadeneira y Cervantes», en «Spiritus vivificat». Actas del V Congreso Internacional «Jóvenes Investigadores Siglo de Oro» (JISO 2015), ed. Maite Iraceburu 
y Carlos Mata Induráin, Pamplona, Servicio de Publicaciones de la Universidad de Navarra, 2016, pp. 33-41.

Forteza, Deborah, «Beasts, Harpies, and Medeas: Tudor Representations in Lope and Calderón», Anuario Calderoniano, 11, 2018, pp. 81-99.

Highley, Christopher, «"A Pestilent and Seditious Book": Nicholas Sander's Schismatis Anglicani and Catholic Histories of the Reformation», Huntington Library Quarterly, 68.1-2, 2005, pp. 151-171.

Johnson, Carroll B., «La española inglesa and the Practice of Literary Production», Viator, 19, 1988, pp. 377-416.

Maravall, José Antonio, Estudios de historia del pensamiento español, serie tercera: El siglo del Barroco, 2. ${ }^{a}$ edición ampliada, Madrid, Cultura Hispánica, 1984.

Olid Guerrero, Eduardo, «The Machiavellian in-Betweeness of Cervantes's Elizabeth |», Cervantes. Bulletin of the Cervantes Society of America, 33.1, 2013, pp. 45-80.

Pineda, Victoria, «La tradición del exemplum en el discurso historiográfico y político de la España imperial», Revista de Literatura, 67, 133, 2005, pp. 31-48.

Quintero, María Cristina, "The Body of a Weak and Feeble Woman": Courting Elizabeth in Antonio Coello's El conde de Sex», en Material and Symbolic Circulation between Spain and England, 1554-1604, ed. Anne J. Cruz, Aldershot/ Burlington (VT), Ashgate, 2008, pp. 71-87.

Ribadeneyra, Pedro de, Historias de la contrarreforma, ed. Eusebio Rey, Madrid, Editorial Católica, 1945.

Sander, Nicolas, Rise and Growth of the Anglican Schism, trans. and notes David Lewis, London, Burns and Oates, 1877.

Stierle, Karlheinz, «Three Moments in the Crisis of Exemplarity: Boccaccio-Petrarch, Montaigne, and Cervantes», Journal of the History of Ideas, 59.4, 1998, pp. 581-595.

Torres, Isabel, «Now You See it, Now You... See it again? The Dynamics of Doubling in La española inglesa», A Companion to Cervantes' "Novelas ejemplares», ed. Stephen F. Boyd, Woodbridge (Suffolk), Tamesis, 2005, pp. 115-133.

Vega, Lope de, La Dragontea, ed. Antonio Sánchez Jiménez, Madrid, Cátedra, 2007.

Vega, Lope de, Rimas humanas y otros versos, ed. Antonio Carreño, Barcelona, Crítica, 1998

Yepes, Diego de, Historia particular de la persecución de Inglaterra y de los martirios más insignes que en ella ha habido, desde el año del Señor 1570; en la cual se descubren los efectos lastimosos de la herejía y las mudanzas que suele causar en las repúblicas, en Madrid, por Luis Sánchez, 1599. 